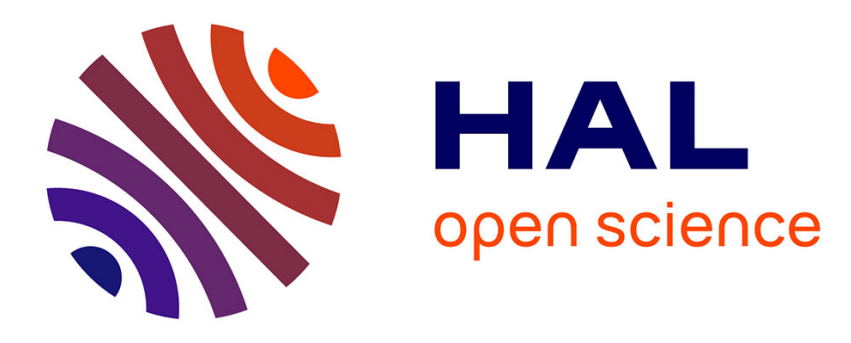

\title{
Solid State Chemical Interaction Between Ti and Al-Si Alloys
}

O. Dezellus, M. Zhe, B. Gardiola, S. Lay, J. Viala

\section{To cite this version:}

O. Dezellus, M. Zhe, B. Gardiola, S. Lay, J. Viala. Solid State Chemical Interaction Between Ti and Al-Si Alloys. Journal of Phase Equilibria and Diffusion, 2021, 10.1007/s11669-021-00914-9 . hal-03353250

\author{
HAL Id: hal-03353250 \\ https://hal.science/hal-03353250
}

Submitted on 23 Sep 2021

HAL is a multi-disciplinary open access archive for the deposit and dissemination of scientific research documents, whether they are published or not. The documents may come from teaching and research institutions in France or abroad, or from public or private research centers.
L'archive ouverte pluridisciplinaire HAL, est destinée au dépôt et à la diffusion de documents scientifiques de niveau recherche, publiés ou non, émanant des établissements d'enseignement et de recherche français ou étrangers, des laboratoires publics ou privés. 


\title{
Solid state chemical interaction between $\mathrm{Ti}$ and $\mathrm{Al}-\mathrm{Si}$ alloys
}

\author{
O. Dezellus ${ }^{1^{*}}$, M. Zhe ${ }^{1}$, B. Gardiola1 ${ }^{1}$ S. Lay ${ }^{2}$, J.C. Viala ${ }^{1}$ \\ ${ }^{1}$ Université Claude Bernard Lyon 1, LMI - UMR CNRS N5615, 43 Bd du 11 novembre 1918, \\ 69622 Villeurbanne Cedex, France
}

2 Univ. Grenoble Alpes \& CNRS, SIMAP, Grenoble INP, 38000 Grenoble, France

\begin{abstract}
Diffusion couples of $\mathrm{Ti}$ and biphasic alloy Al-7wt\% $\mathrm{Si}$ were produced and heat-treated at $535^{\circ} \mathrm{C}$ for between 1 and 200 hours. The nature and thickness of the phases present in the reaction layer sequence were characterized using conventional techniques such as microprobe analysis and transmission electron microscopy. For short interaction times the interfacial reaction layer consists mainly of silicides, whereas aluminides are formed after times longer than $40 \mathrm{~h}$. This variation in the spatial reaction layer sequence over time is explained by the biphasic nature of one of the diffusion couple end-members, with high activity for both elements, and by the huge difference between the composition of the first phase formed at the initial interface and the average composition of the biphasic end-member. This situation, which can no doubt be observed in other systems, illustrates the difficulty of confirming that a true diffusion path has been attained in a diffusion couple. Most of the criteria that were first proposed by Kirkaldy and Brown, can apparently be respected, but the system could continue shifting over time towards a more stable configuration. In some systems, as in the case of $\mathrm{Al}-\mathrm{Si}-\mathrm{Ti}$, the slow kinetics can be problematic, making it impossible to predict a radical change in material properties.
\end{abstract}

Corresponding Author: Fax: +33472440618

email address: olivier.dezellus@univ-lyon1.fr

\section{Introduction}

The diffusion couple technique is powerful and widely used in solid state and materials science. Diffusion couples can be used to determine basic academic data such as diffusion data as well as phase equilibria [1,2], provided that the phase sequence formed in the interdiffusion zone of a diffusion couple can be identified with a diffusion path in the equilibrium phase diagram of the chemical system considered. The conditions required for a reaction layer sequence to be a diffusion path were first published by Kirkaldy and Brown in 1963 [3] and more recently reviewed by Morral [4]. But the main interest of the diffusion path concept is undoubtedly its inverted use as a guide to predict the microstructure resulting from the interaction of two different materials in applications to design various industrial processes such as brazing, diffusion bonding and carburizing. Two main types of solid-state diffusion couple can be distinguished: the first one corresponds to couples where the initial end-members belong to adjacent phase fields of the equilibrium phase diagram. For binary systems, there is only one solution and it can be calculated using the conventional approach to diffusion by solving Fick's laws, which is now possible using a software suite such as DICTRA. For ternary systems, determination of the diffusion path is much less straightforward. Many authors have proposed theoretical approaches to this problem of determining how an interfacial microstructure can change during an interdiffusion process, considering the possible dissolution or formation of precipitate in the two-phase domain as well as instabilities of interfaces [5-7]. This approach has proved able to be predictive in several ternary systems $[8,9]$. The second type of solid-state diffusion couple is characterized by the formation of new phases at interfaces during the interdiffusion process, leading to what is called a reaction-diffusion process and a new complexity increment. The binary system is still the simplest case, as it can be addressed using the conventional equations of diffusion [10-12]. For both binary and higher-order systems, it has been shown that a complex microstructure can be obtained, including patterning of the spatial reaction layer sequence, because of the dissociation of the Kirkendall plane, which is not necessarily unique in such systems [13-15]. All these 
phenomena make it difficult to predict the reaction layer sequence in a reactive multiphase ternary system. In such conditions, the rules initially defined by Kirkaldy and Brown to determine the diffusion path are the first ones to consider when studying a new system [3].

In identifying a sequence of reactions to a diffusion path, the first condition is local equilibrium at each interface in the interdiffusion zone. This implies the establishment of stationary conditions across the interdiffusion zone, where all the phases must be present and develop concomitantly with their own kinetic laws. In multicomponent systems, however, the diffusion couple could consist of several multiphasic domains with a specific kinetics of nucleation and growth. As a consequence, the spatial sequence of phases characterising the diffusion couple is only obtained after a temporal sequence during which equilibrium phases will form successively. During this non-stationary temporal sequence, the interfacial layer sequence can deviate from the equilibrium composition of the diffusion couple: in this case the main question is how can one be sure that the reaction layer sequence observed corresponds to an equilibrium diffusion path? One of the most commonplace techniques for ensuring that equilibrium is reached is to increase the diffusion time, which must not be associated with a change in the nature of the observed phases. Of course, this solution does not provide definitive evidence of equilibrium as the duration of the transitory state is by definition unknown, but it does appear to be the most pragmatic one. The present paper gives an illustration of a reactive interdiffusion process that is characterized by the existence of a long transitory state followed by an abrupt change in the reaction layer sequence towards what should be the final equilibrium diffusion path.

The system that consists of an Al-Si alloy and a Ti substrate is interesting not only for academic purposes but also for many applications in industry, where it is already being used or considered for future developments in several technologies. In the aeronautic and automotive industries, weight saving is nowadays a major factor in improving energy efficiency. Because of their attractive properties, such as low density and high specific stiffness, light aluminium alloys are increasingly being used to replace cast-iron or steel components. However, they are not able to sustain a high load level due to a low Young's modulus and poor damage tolerance, and several technological solutions are being considered to support their development. These include strengthening using ceramic particles, joining with stiffer materials such as $\mathrm{Ti}$, or local reinforcement through insertion moulding. Furthermore, it is well known that most aluminium alloys, whether wrought or casting alloys, have to be heat-treated in order to achieve their optimum mechanical properties: precipitation hardening treatment for 2000, 4000, 6000 and 7000 series alloys, or annealing treatment for 3000 and 5000 series alloys. Whichever method is used for reinforcement, heat treatment can strongly influence the chemistry of the interface between the aluminium alloy and the reinforcement material. The present study addresses the case of a Ti insert moulding in an Al-7Si-0.3Mg (in wt.\%) aluminium alloy (42100 and A356.2 according to NF EN 1676 and ASTM standards respectively) and the influence of the solution treatment step of a T6-type heat treatment on the chemistry of the interface. As explained above, in addition to the usual heat treatment times of a few hours, extended interdiffusion times of a few tenths or hundreds of hours are also considered in order to increase the probability of characterizing the final equilibrium diffusion path in this ternary multiphase diffusion couple.

\section{Experimental section}

Bimetallic samples were processed using a three-step procedure that is described in detail hereafter: firstly, a sound metallurgical bond is established between the Ti substrate and an Al-Si alloy using a liquid aluminizing procedure [16-18]; secondly, the aluminized Ti sheet is overmoulded in order to constitute a semi-infinite diffusion couple, and finally the solid-state heat treatment is performed at $535^{\circ} \mathrm{C}$ for different times. The Al alloys were processed from an Al$7 \mathrm{wt} . \% \mathrm{Si}-0.3 \mathrm{wt} . \% \mathrm{Mg}$ casting alloy supplied by Alcan ${ }^{\circledR}$ and referred to as $\mathrm{A} 356.2$ according to ASTM standards (composition given in Table 1). As no $\mathrm{Mg}$ segregation was detected in the phases formed in the interfacial reaction layer sequence by any of the experimental techniques used in the present study, Mg is considered as a neutral alloying element. As a consequence, the alloy will be simply referred to as $\mathrm{Al}-7 \mathrm{wt}$ \% $\%$ Si hereafter. 


\begin{tabular}{lccccccccccc}
\hline Element & $\mathrm{Si}$ & $\mathrm{Fe}$ & $\mathrm{Cu}$ & $\mathrm{Mn}$ & $\mathrm{Mg}$ & $\mathrm{Ni}$ & $\mathrm{Zn}$ & $\mathrm{Pb}+\mathrm{Sn}$ & $\mathrm{Sb}$ & $\mathrm{Ti}$ & Others \\
\hline \hline Min. & 6.7 & & & & 0.3 & & & & & & \\
Max. & 7.3 & 0.14 & 0.02 & 0.04 & 0.4 & 0.02 & 0.04 & 0.02 & 0.16 & 0.15 & 0.1 \\
tolerance \pm & 0.2 & 0.01 & 0.01 & 0.01 & 0.02 & 0.01 & 0.01 & 0.01 & 0.02 & 0.01 &
\end{tabular}

Table 1: The composition (wt.\%) of the A356.2 alloy supplied by ALCAN.

Titanium of commercial purity (Grade 9) was provided by Goodfellow ${ }^{\circledR}$ as $1 \mathrm{~mm}$ thick sheets (typical composition in wt ppm: Al 500, Co 2, Cr 500, Cu 200, Fe 300, Mg 20, Mn 500, Ni 500, Si 200, Sn 200, Ta 10, V 500, Ti balance). All sheets received the same surface preparation by mechanical abrasion on $\mathrm{SiC}$ papers under water to a mean surface roughness of about $3 \mu \mathrm{m}$, rinsing and drying. This procedure was performed immediately before immersion in order to prevent oxidation of the Ti sheets.

The Al-7wt.\%Si alloy was cut into small pieces that were degreased in an ultrasonic bath (first ethanol and then acetone), placed in a ceramic oxide crucible and heated above their melting temperature by direct radio-frequency coupling. As is the case with many metals with a high affinity for oxygen, good wetting and a strong metallurgical bond across the liquid-solid interface can only be obtained after removal of the native oxide film layer on the Ti [19-21]. Removal is promoted through the dissolution of $\mathrm{Ti}$ in the liquid alloy and is therefore favoured in the case of melts with a low Ti content. In this case, however, the growth of reaction layers is limited by their dissolution in the bath until the solubility limit of $\mathrm{Ti}$ is reached $(0.2 \mathrm{wt} . \%$ according to Perrot et al. [22]). Before the Ti plates were immersed, the bath was stirred regularly and the surface oxide skin was removed. The bath temperature was measured with a precision greater than $\pm 0.2^{\circ} \mathrm{C}$ by plunging a $\mathrm{K}$-type $(\mathrm{Ni} / \mathrm{Cr})$ thermocouple in the melt. It should be noted that, with a bath heated to $740^{\circ} \mathrm{C}$, immersion of a Ti plate led to a temperature decrease of about $10^{\circ} \mathrm{C}$. Therefore, interface reactions were considered to develop at a temperature of $730 \pm 5^{\circ} \mathrm{C}$. After 2 min of immersion, the Ti plates were removed from the bath and immediately quenched in water. At the end of this aluminizing step each $\mathrm{Ti}$ sheet was surrounded by a thin Al alloy layer with a typical thickness of about $100 \mu \mathrm{m}$.

After solidification and cooling to room temperature, the aluminized Ti sheet was overmoulded with a new thick layer of Al-7wt.\%Si alloy in order to drastically increase the thickness of the Al-Si end-member of the couple to $4 \mathrm{~mm}$ and therefore constitute a semi-infinite diffusion couple able to sustain further lengthy heat treatments. Overmoulding is performed in a graphite crucible heated by radio-frequency coupling. The aluminized Ti sheet is placed in the crucible, which is then filled with small pieces of Al-7wt.\%Si and heated until the alloy has melted. The temperature of this second stage is also measured by plunging a $\mathrm{K}$-type $(\mathrm{Ni} / \mathrm{Cr})$ thermocouple in the liquid and set at a value of $680 \pm 5^{\circ} \mathrm{C}$. After 2 min of contact, the power supply is switched off and solidification occurs slowly.

After cooling, the whole $6 \mathrm{~cm}$-long overmoulded Ti sheet is heat-treated in air at $535^{\circ} \mathrm{C}$ for different lengths of time varying between $4 \mathrm{~h}$ and $200 \mathrm{~h}$. Some additional experiments were also performed at different temperatures and for a constant time of $90 \mathrm{~h}$ in order to determine the temperature sensitivity of the whole growth process.

After treatment, the specimens were embedded in resin to prepare polished sections that were examined by optical microscopy (OM) and scanning electron microscopy (SEM) and then characterized by electron probe microanalysis (EPMA), the third-mentioned analysis being carried out using a Camebax apparatus (Cameca). Concentration profiles were thus established point by point with a $0.5 \mu \mathrm{m}$ step at the crossing of reaction zones. For the longer heat treatment times the interfacial reaction layer was also characterized using X-Ray diffraction (XRD) after progressive abrasion in order to record the XRD pattern at different depths.

Transmission electron microscopy (TEM) samples of about $25 \times 25 \times 0.1 \mu \mathrm{m}^{3}$ were prepared from 
cross-sections using a JEM 9320 focused ion beam (FIB) with a Ga+ ion accelerating voltage of $30 \mathrm{kV}$. TEM was performed using a $3010 \mathrm{JEOL}$ microscope operated at $300 \mathrm{kV}$ for bright-field (BF) imaging, selected area diffraction (SAD) and energy dispersive spectroscopy (EDS) chemical analysis.

\section{Results}

\subsection{As-cast specimen.}

Fig. 1 shows a typical Ti/ Al-7wt.\%Si interface after aluminizing at $730^{\circ} \mathrm{C}$ for $2 \mathrm{~min}$. A very thin interfacial reaction layer of about $1 \mu \mathrm{m}$ is observed. The nature of this reaction layer was determined by X-ray diffraction. For that purpose, the Al-7wt.\%Si layer resulting from the aluminizing step was removed by immersion in a $\mathrm{NaOH}$ bath (10wt.\%). The recorded diffraction pattern (see Fig. 2a) obtained is typical for $\left(\mathrm{Al}_{(1-x)} \mathrm{Si}_{\times}\right)_{3} \mathrm{Ti}$ corresponding to the binary compound $\mathrm{Al}_{3} \mathrm{Ti}$ with some Al:Si substitution [23]. The lattice parameters of $\mathrm{Al}_{3} \mathrm{Ti}$ are modified by the substitution, and a Rietveld analysis of the diffraction pattern led to $a=0.38009 \mathrm{~nm}$ and $c=0.85727$ $\mathrm{nm}$. It should be noted that both phases present a preferential orientation: Ti because the sheet was rolled, and $\mathrm{Al}_{3} \mathrm{Ti}$ because the first crystals nucleated and grew on an oriented Ti surface (see Fig. 1). EPMA analyses performed on a cross-section confirmed the presence of this compound with a Si quantity of approximate 12at.\%. It should be noted that the Si content and the lattice parameters for the $\mathrm{Al}_{3} \mathrm{Ti}$ phase are highly consistent with the results found in the literature [23].

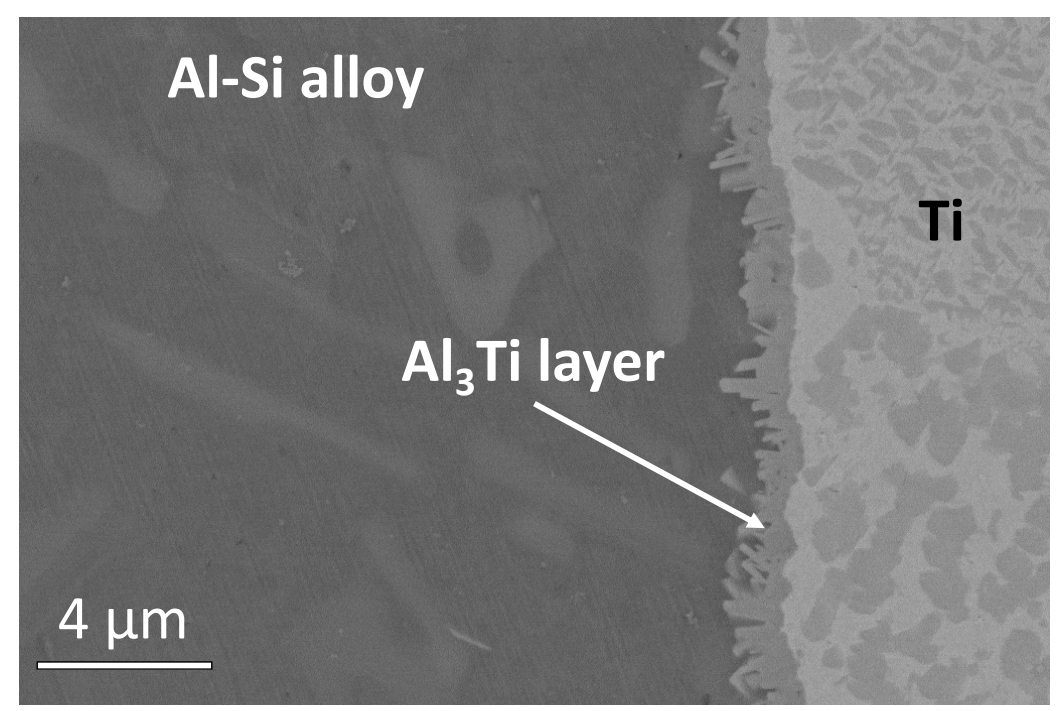

Fig. 1: SEM micrograph of as-cast sample showing the thin $\mathrm{Al}_{3} \mathrm{Ti}$ reaction layer

The same procedure was used to characterize the interfacial area after overmoulding, leading to the XRD pattern in Fig. 2b. It appears from this pattern that, during slow cooling of the Al-7wt.\%Si /Ti assembly in the graphite crucible, $\mathrm{Al}_{3} \mathrm{Ti}$ is replaced by one of the $\tau$ ternary compounds $\tau_{1}$ or $\tau_{2}$. Both compounds have a similar crystal structure: $\tau_{1}$ is isostructural with $\mathrm{Zr}_{3} \mathrm{Al}_{4} \mathrm{Si}_{5}$ with a space group 14/amd [24], while the space group of $\tau_{2}$ is $\mathrm{CmCm}$ with a $\mathrm{ZrSi}_{2}$ prototype and a Strukturbericht designation of C49 [25]. As a consequence, they can barely be distinguished in terms of their XRD patterns, especially given their micrometre-thick interfacial layers with preferential orientation. The structural and compositional similarities between these two compounds have already led some authors to misidentifications and ambiguous results [26]. However, a careful Rietveld analysis of the diffraction pattern gives a number of clues indicating that the ternary compound is $\tau_{1}(a=0.35872 \mathrm{~nm}, c=2.71059 \mathrm{~nm})$. First of all, while the two most intense peaks attributed to the ternary compounds $(2 \theta=40.77$ and 50.9$)$ can correspond both to $\tau_{1}$ and $\tau_{2}$, they are better described by the 116 and 020 reflections of $\tau_{1}$. Once the lattice parameters of the phases have been adjusted using the next two most intense peaks, a distinction between $\tau_{1}$ and $\tau_{2}$ can be made in the high angle range: the 220 reflection of $\tau_{1}$ is expected at $2 \theta=74.68$ while the closest reflections of $\tau_{2}$ in this $2 \theta$ range are $0-10-1$ at $2 \theta=73.18$ and 202 at $2 \theta=75.4$. As a consequence, the presence of a single peak at $2 \theta=74.67$ is a strong indication that 
the main ternary compound detected after aluminizing and overmoulding is $\tau_{1}$, even though $\tau_{2}$ should also be present as a minor phase: an indication is given by the peak shape of $\tau_{1}$ reflections that can be understood by considering overlapping with $\tau_{2}$. Moreover, $\tau_{1}$ and $\tau_{2}$ can barely be distinguished through their compositions as their respective chemical formulae differ only slightly, by a few atomic percent [27]. However, when studying the reactivity in solid state between Ti and an $\mathrm{Al}-7 \mathrm{wt} . \% \mathrm{Si}$ alloy, the distinction between the two ternary compounds is second-order information and it is not essential to understand and elucidate the mechanisms of interaction. As a consequence, in the following discussion, the distinction between $\tau_{1}$ and $\tau_{2}$ will be systematically neglected and both phases will be considered as a unique ternary compound and noted as being $\tau$.

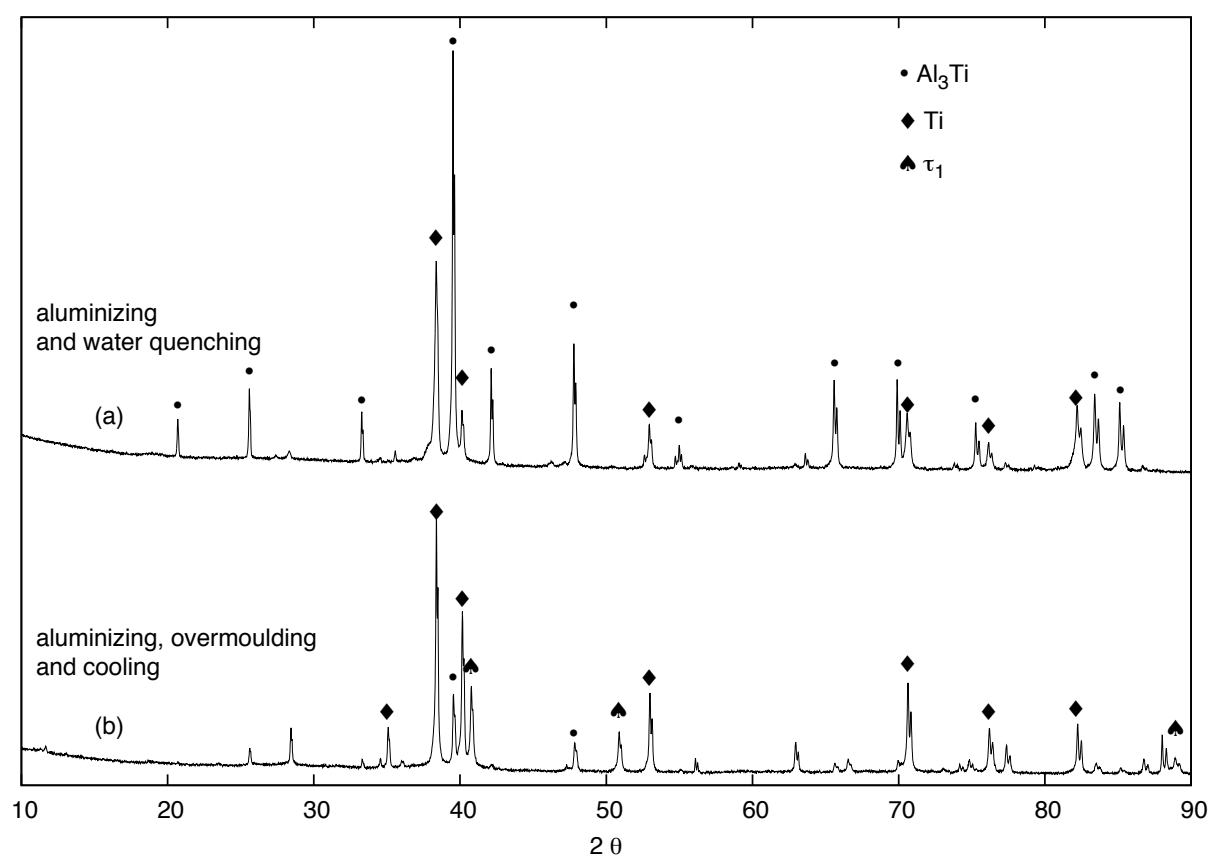

Fig. 2: XRD pattern recorded on the reaction layer formed between Al-7wt.\%Si alloy and $\mathrm{Ti}$ sheet after removal of Al-7wt.\%Si aluminizing layer by basic dissolution in $\mathrm{NaOH}$ : (a) after the first aluminizing step followed by water quenching; (b) after aluminizing, overmoulding and cooling in a graphite die at a slow cooling rate

Fig. 3 shows two TEM images of the interfacial reaction zone between Ti and the Al-7wt.\%Si alloy after aluminizing and overmoulding. The white area in the lower part of the image corresponds to the aluminium alloy while the $\mathrm{Ti}$ substrate is in the upper right corner. Two distinct layers are observed in the interfacial area: an internal layer in contact with the Ti substrate, consisting of small grains with a typical nanometric size, and a second layer with elongated grains growing towards the Al-7wt.\%Si alloy. The structure (SAD) and the composition (EDS) of both layers performed on some grains of Zone 2 confirm the presence of the $\tau$ phase. 


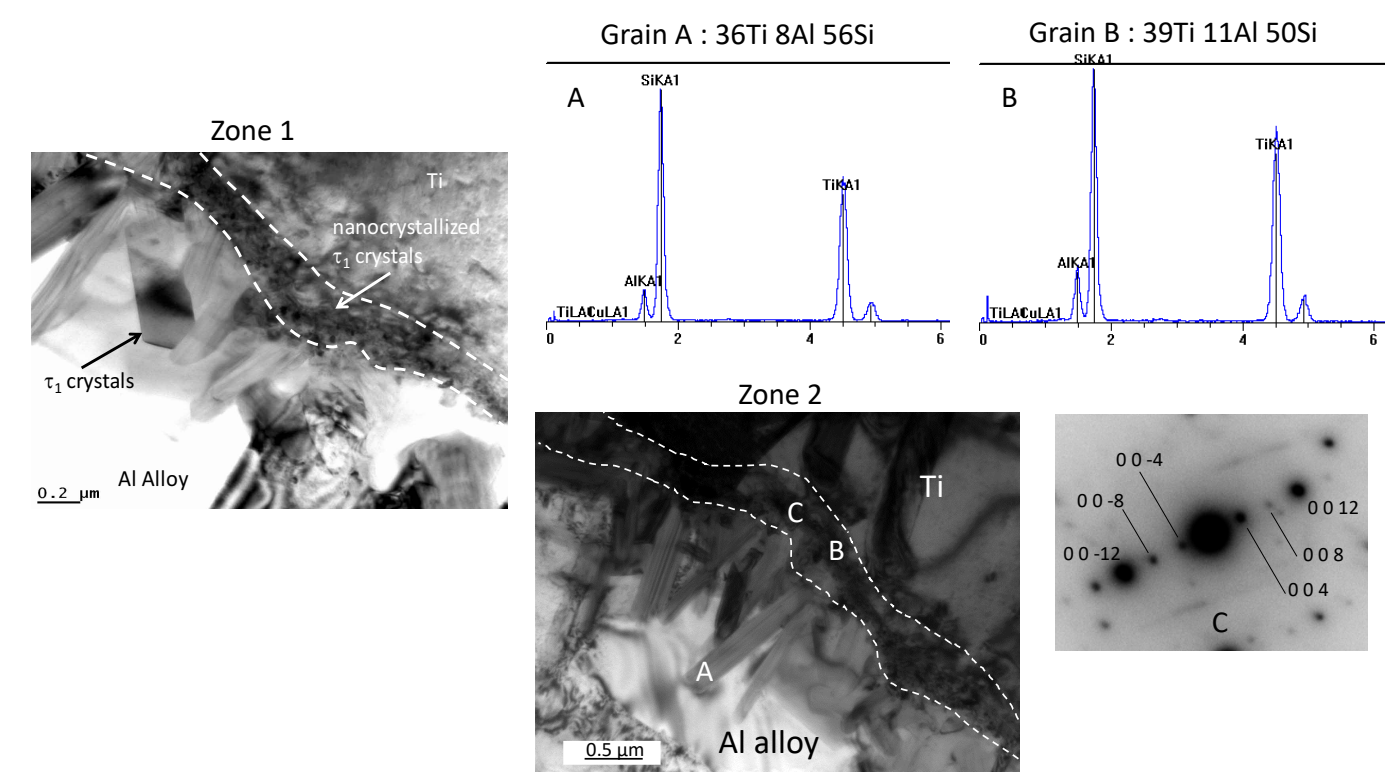

Fig. 3: TEM micrographs of the interfacial region between Ti and the Al-7wt.\%Si alloy after aluminizing at $730^{\circ} \mathrm{C}$ and overmoulding at $680^{\circ} \mathrm{C}$. EDS analysis and Selected Area Electron Diffraction diagram performed on some grains of Zone 2 confirm the presence of $\tau$ phase.

\subsection{Heat treatment at $535^{\circ} \mathrm{C}-$ Effect of time.}

During heat treatment of the bimetallic interface at $535^{\circ} \mathrm{C}$, the main feature observed is a drastic change in the $\mathrm{Al}-\mathrm{Si}$ alloy microstructure characterized by the consumption of Si particles from the Al-7wt.\%Si alloy near the substrate interface and the rounding of Si particles (see Fig. 4). 

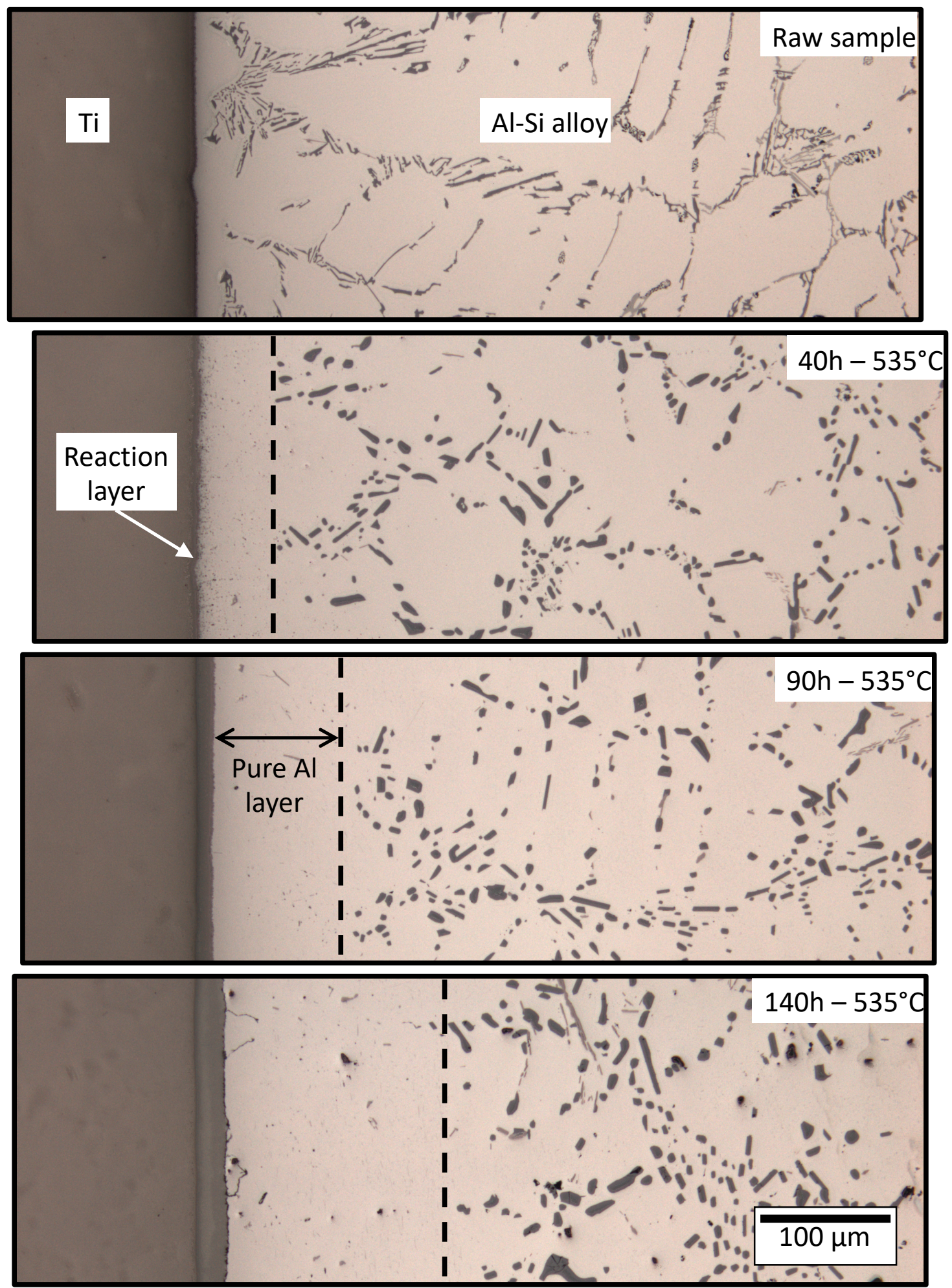

Fig. 4: Optical micrographs of the Ti/Al-Si7wt.\%Si interface after aluminizing and overmoulding, and several heat treatment times at $535^{\circ} \mathrm{C}: 40 \mathrm{~h}, 90 \mathrm{~h}$ and $140 \mathrm{~h}$ (magnification is the same for all micrographs).

In actual fact, the distance between the $\mathrm{Al}-7 \mathrm{wt} . \% \mathrm{Si} /$ reaction layer interface and the first $\mathrm{Si}$ crystals in the alloy increases to $200 \mu \mathrm{m}$ after $200 \mathrm{~h}$ of treatment (see Fig. 5). At the same time, the interfacial reaction layer thickness increases from a few micrometres before heat treatment to about $35 \mu \mathrm{m}$ after $200 \mathrm{~h}$ at $535^{\circ} \mathrm{C}$. 

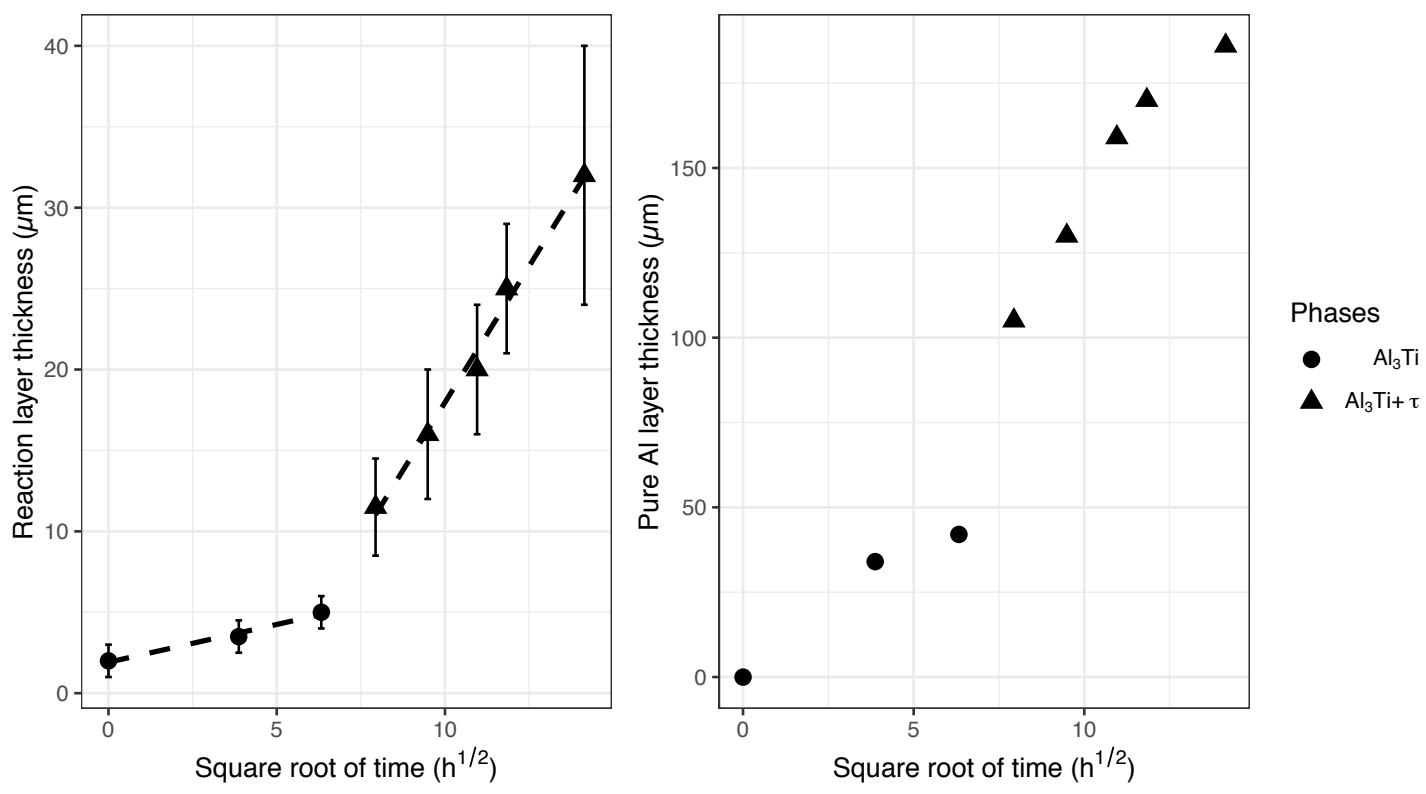

Fig. 5: Left hand side: variation in the total thickness of the interfacial reaction layer with up to $200 \mathrm{~h}$ of treatment at $535^{\circ} \mathrm{C}$. Filled circles correspond to a one-phase reaction layer ( $\tau$ phase), while filled triangles correspond to a biphasic reaction layer with the formation of $\left(\mathrm{Al}_{(1-x)} \mathrm{Si}_{\mathrm{x}}\right)_{3} \mathrm{Ti}$.

Right hand side: variation in the thickness of the pure fcc-Al layer that is formed from the Al$7 \mathrm{wt} . \% \mathrm{Si}$ matrix by the total consumption of Si platelets. Once again, filled circles correspond to a one-phase reaction layer, while filled triangles correspond to a biphasic reaction layer.

A comparison of XRD patterns obtained before and after $15 \mathrm{~h}$ treatment reveals that the increase in reaction layer thickness of about $2 \mu \mathrm{m}$ is accompanied by a significant decrease in the ratio between $\mathrm{Al}_{3} \mathrm{Ti}$ and the $\tau$ compound (see Fig. 6). This result is consistent with the EPMA analyses and indicates that, after $15 \mathrm{~h}$ at $535^{\circ} \mathrm{C}$, the $\tau$ compound can be considered as the main phase in the reaction layer. It should be noted that the distance between Si crystals in the Al-7wt.\%Si alloy and the interface is already significant after this treatment time, with a typical value of about 35$40 \mu \mathrm{m}$ (see Fig. 5). 


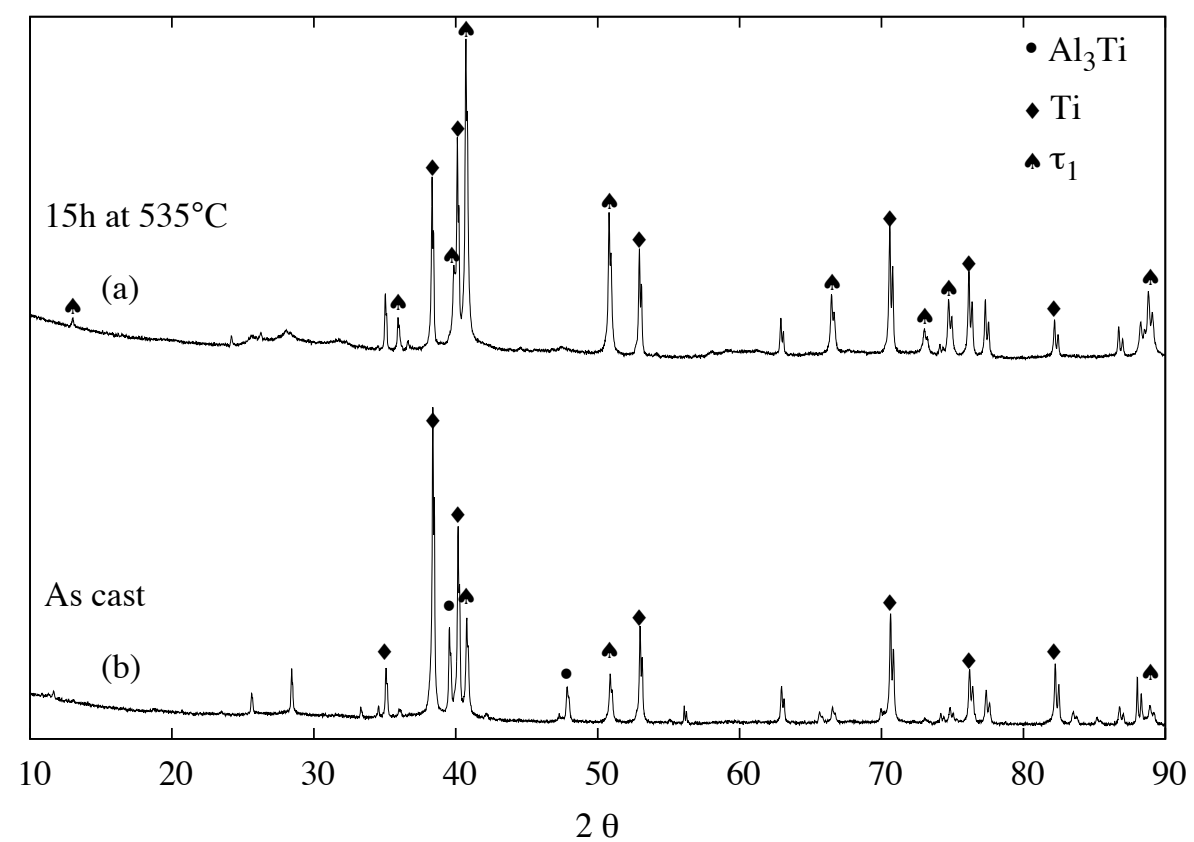

Fig. 6: comparison of XRD patterns recorded on the interfacial reaction layer after removal of Al-

7wt.\%Si alloy by basic dissolution in $\mathrm{NaOH}$ between: (a) a sample after $15 \mathrm{~h}$ of isothermal holding at $535^{\circ} \mathrm{C}$, and (b) an as-cast sample after aluminizing and overmoulding.

When holding time is increased, a dramatic change in the reaction layer growth rate is observed after about $40 \mathrm{~h}$ of treatment. Moreover, within the error bars on the experimental measurements the main trend between thickness and the square root of time is linear for the two stages, before and after $40 \mathrm{~h}$; this is represented in Fig. 5. The experimental points representing the reaction layer thickness fit satisfactorily with a parabolic growth law where $x$ and $t$ are expressed in metres and seconds:

$x^{2}=\mathrm{K} \cdot t-\mathrm{b}$

The values of the rate constant $\mathrm{K}$ in the two stages are, respectively, $\mathrm{K}=1.45 \times 10^{-16} \mathrm{~m}^{2} . \mathrm{s}^{-1}$ before $40 \mathrm{~h}$ of treatment, and $\mathrm{K}=1.752 \times 10^{-15} \mathrm{~m}^{2} . \mathrm{s}^{-1}$ after $40 \mathrm{~h}$ of treatment. The net increase in the growth rate by one order of magnitude observed at a holding time of about $40 \mathrm{~h}$ is associated with a change in the chemical composition of the interfacial reaction layer. The variation in the concentration profiles across the reaction zone when the holding time at $535^{\circ} \mathrm{C}$ is increased gives some indications as to the temporal sequence of phase formation during the interdiffusion process. Firstly, and in keeping with the XRD analysis, for short holding times, a silicon-rich layer that counts as a $\tau$ phase is observed (see as-cast sample in Fig. 7 ). After $15 \mathrm{~h}$ at $535^{\circ} \mathrm{C}$, the thickness of the $\tau$ phase increases slightly and the profiles are characterized by an asymmetrical shape indicating the formation of a finely dispersed multiphase area near the Ti interface. It should be noted that the probe size is still too large to obtain a pure analysis of the phases. When holding time is increased, after $90 \mathrm{~h}$ at $535^{\circ} \mathrm{C}$, the reaction layer thickness becomes sufficient to obtain constant values of both elements within some of the reaction zone phases. The main part of the concentration profile corresponds to the $\tau$ phase with about 50at.\%Si and 30at.\%Ti. An increase in $\mathrm{Al}$ content from $10 \mathrm{at} . \%$ in the $\tau$ phase to $40 \mathrm{at} . \%$ near the Ti interface is clearly observed on the Al profile across the reaction layer. This "bump" on the Al profile develops during further treatment, and a thick layer of the $\left.\left(\mathrm{Al}_{(1-\mathrm{x})} \mathrm{Si}_{\mathrm{x}}\right)_{3}\right)_{3} \mathrm{Ti}$ aluminide with about $14 \mathrm{at} . \% \mathrm{Si}$ is observed after $200 \mathrm{~h}$ of holding time. The presence of this aluminide is also noted at the external interface of the reaction layer, near the Al-7wt.\%Si alloy, even though the smaller thickness makes it more difficult to identify. As a consequence, the first kinetic regime observed on Fig. 5, before $40 \mathrm{~h}$ of holding time, is associated mainly with the growth of the $\tau$ phase. Thickening of this silicon-rich phase (about $47 \mathrm{wt} . \% \mathrm{Si}$, i.e. $1.844 \mathrm{~g}$ of Si per $\mathrm{cm}^{-3}$ ) by $1 \mu \mathrm{m}$ consumes the whole Si content of a $10 \mu \mathrm{m}$-thick layer of the Al-7wt.\%Si alloy, leading to the disappearance of the Si particles observed in Fig. 4. Next, in a second stage, rapid growth of a $\left(\mathrm{Al}_{(1-x)} \mathrm{Si}_{\mathrm{x}}\right)_{3} \mathrm{Ti}$ aluminide, mainly at the inner interface 
between $\mathrm{Ti}$ and $\tau$, is observed. Once again, since the silicon content of the growing phase is greater than that of the Al- $7 \mathrm{wt} . \% \mathrm{Si}$ alloy $\left(0.318 \mathrm{~g}\right.$ of Si per cm $\mathrm{cm}^{-3}$ against $0.187 \mathrm{~g}$ of Si per cm${ }^{-3}$ for the alloy), thickening of the interfacial reaction layer leads to consumption of Si particles in the alloy as observed in Fig. 4. During this second stage, the individual growth rates of the two phases can not be determined as in the first stage. The $\left(\mathrm{Al}_{(1-\mathrm{x})} \mathrm{Si}_{\mathrm{x}}\right)_{3} \mathrm{Ti}$ aluminide is not present as a clear single layer but rather as a second phase embedded in the initial $\tau$ layer, even leading to the formation of biphasic domains especially nearby the Ti interface. As a consequence, the growth rate that is evaluated corresponds to the one of the whole reaction layer and its increase compared to the one calculated for the first stage evidences the influence of the $\left(\mathrm{Al}_{(1-x)} \mathrm{Si}_{\mathrm{x}}\right)_{3} \mathrm{Ti}$ aluminide.

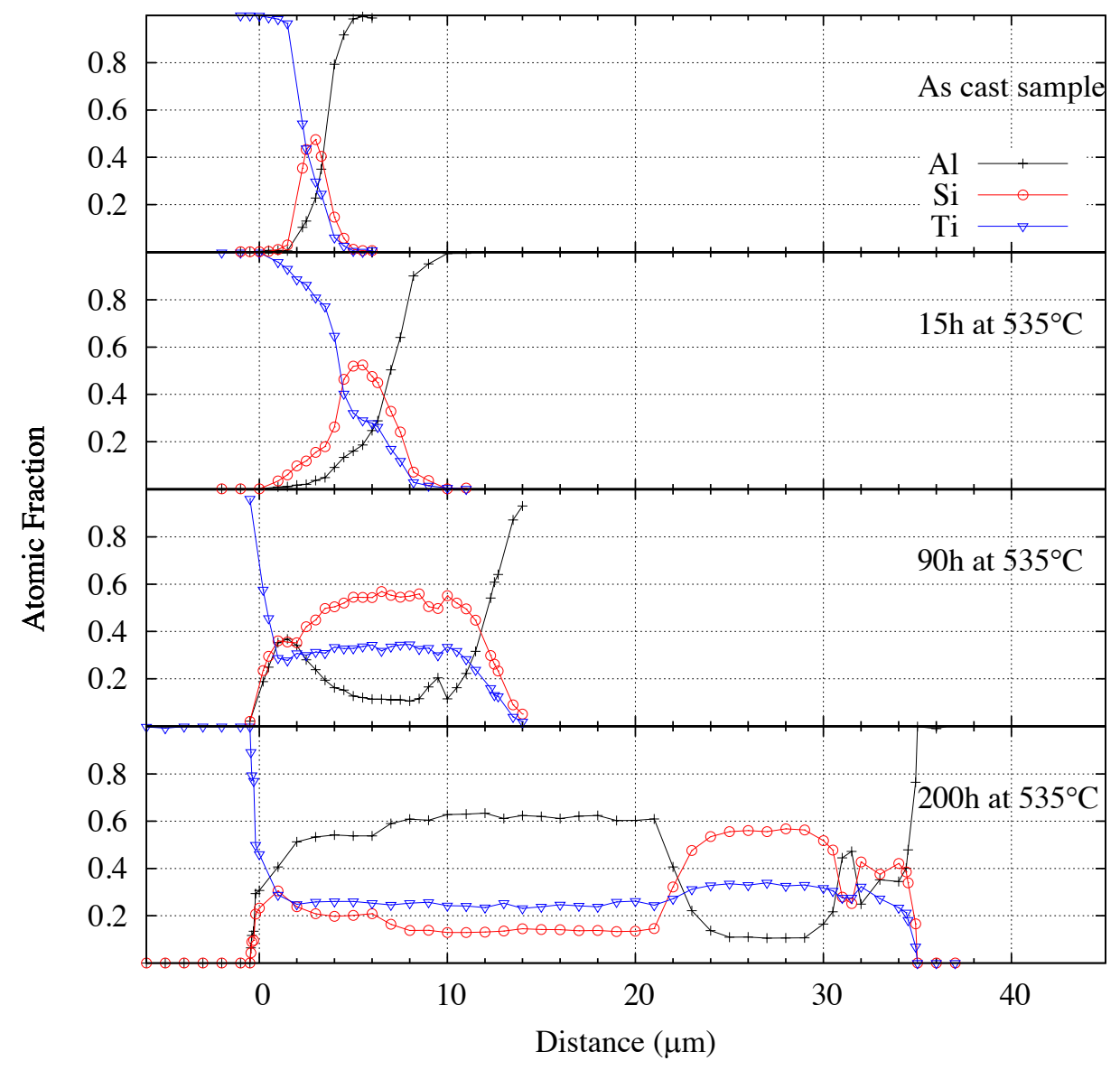

Fig. 7: composition profiles determined by EPMA analyses across the reaction layers formed between Ti and the Al-7wt.\%Si alloy, (a) for the as-cast sample, and after (b) 15h, (c) 90h, (d) $200 \mathrm{~h}$ of isothermal holding at $535^{\circ} \mathrm{C}$.

Fig. 8 shows an image of the interfacial reaction zone between Ti and the Al-7wt.\%Si alloy after aluminizing, overmoulding and $160 \mathrm{~h}$ of treatment at $535^{\circ} \mathrm{C}$. This micrograph confirms the development of $\left(\mathrm{Al}_{(1-\mathrm{x})} \mathrm{Si}_{\mathrm{x}}\right)_{3} \mathrm{Ti}$ (light grey layer) in the interfacial reaction layer. The aluminide forms both at the inner and outer interfaces of the interfacial reaction zone. Moreover, one can observe the persistence of a layer of $\tau$ that appears to be dislocated into two sublayers separated by a thick band of $\left.\left(\mathrm{Al}_{(1-x)}\right) \mathrm{Six}_{\mathrm{x}}\right)_{3} \mathrm{Ti}$. 


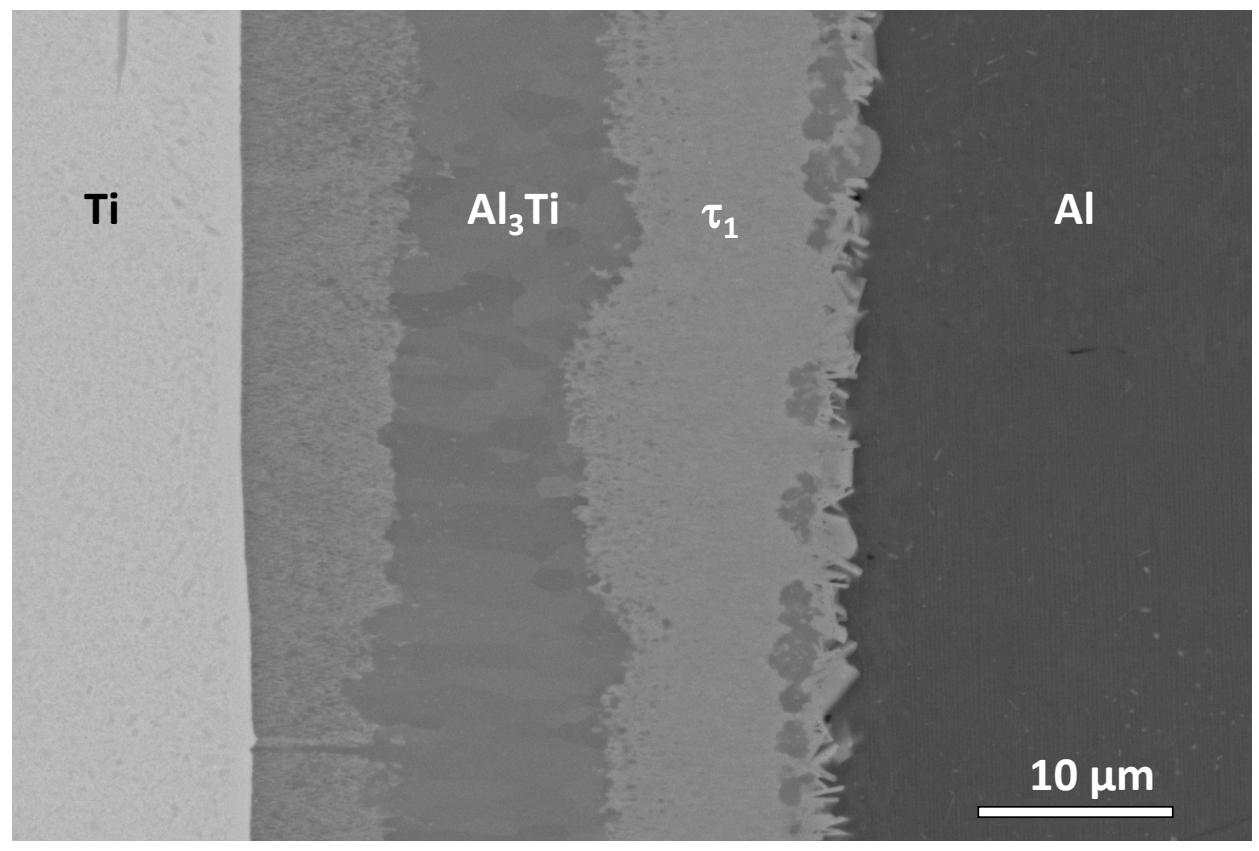

Fig. 8: SEM micrograph of interface between Ti and the Al-7wt.\%Si alloy after $200 \mathrm{~h}$ of heat treatment at $535^{\circ} \mathrm{C}$ showing the development of $\left(\mathrm{Al}_{(1-x)} \mathrm{Si}_{\mathrm{x}}\right)_{3} \mathrm{Ti}$ through the whole interdiffusion zone.

Fig. 9 shows a view of the inner part of the interfacial reaction layer obtained by TEM. This area was sampled using an FIB in the first $20 \mu \mathrm{m}$ near the interface with the Ti substrate. Fig. 9 also shows a diffraction pattern that was obtained on a selected grain (labelled Diff9 on the micrograph). Several SAD analyses were performed on sufficiently large single grains, and all of them correspond to the $\mathrm{Al}_{3} \mathrm{Ti}$ aluminide structure.

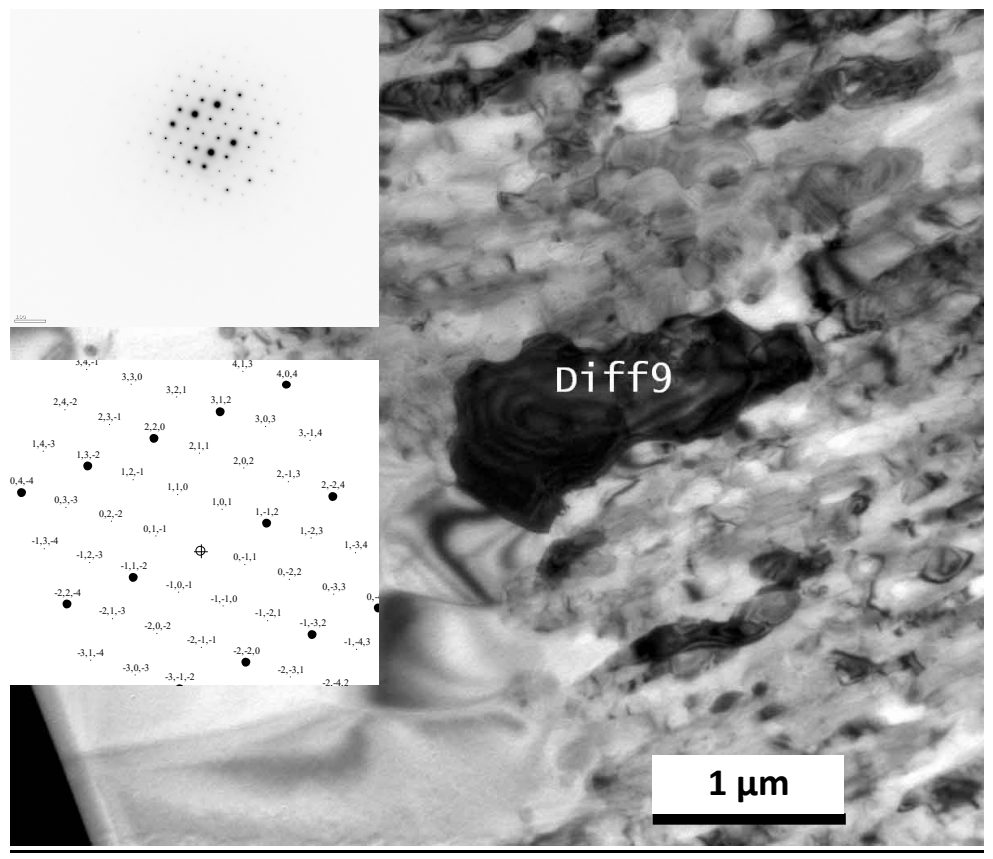

Fig. 9: TEM micrograph of the interfacial region between Ti and the Al-7wt.\%Si alloy after aluminizing at $730^{\circ} \mathrm{C}$, overmoulding at $680^{\circ} \mathrm{C}$ and $160 \mathrm{~h}$ of treatment at $535^{\circ} \mathrm{C}$ : (a) micrograph, (b) characteristic SAD patterns taken from the black grain in 8a, and (c) calculated SAD pattern of $\mathrm{Al}_{3} \mathrm{Ti}$ along the $<111>$ direction. 


\section{Discussion}

The reactivity between a Ti substrate and an $\mathrm{Al}-7 \mathrm{wt} . \% \mathrm{Si}$ alloy described in the present study is characterized not only by the development of a spatial sequence in the interfacial layer but also by an interesting temporal sequence. A time-dependent sequence of intermediate layers is observed, making it difficult to determine the expected stationary reaction layer sequence. The variations in the compound layer sequence during heat treatment are represented as scale drawings in Fig. 10. On this figure, isothermal sections of the Al-Si-Ti phase diagram at $535^{\circ} \mathrm{C}$ are also schematically represented according to the review performed by Perrot et al. [22] and the recent modelling by Liu [23]. It should be noted that the domain of the fcc-Al solid solution is enlarged in order to facilitate the representation of the reaction layer sequence.

\subsection{Aluminizing at $730^{\circ} \mathrm{C}$}

It appears from Fig. 2 that the nature of the phase formed during immersion of the $\mathrm{Ti}$ in the Al$7 \mathrm{wt} . \% \mathrm{Si}$ bath at $730^{\circ} \mathrm{C}$ is the titanium aluminide compound $\mathrm{Al}_{3} \mathrm{Ti}$ with some $\mathrm{Al} / \mathrm{Si}$ substitution. This result is consistent with the projection of monovariant lines in the ternary Al-Si-Ti ternary system proposed by Dezellus et al. [27] and modelled by Liu et al. [23]. Indeed, according to Liu et al., $\mathrm{Al}_{3} \mathrm{Ti}$ is the phase in equilibrium with $7 \mathrm{wt} . \% \mathrm{Si}$ liquid alloy from $677^{\circ} \mathrm{C}$ to $1000^{\circ} \mathrm{C}$. However, isothermal sections of the ternary system around $535^{\circ} \mathrm{C}$ clearly indicate that this compound is not in equilibrium with a solidified $7 \mathrm{wt} . \% \mathrm{Si}$ alloy that consists of an intimated mixture of Al solid solution and Si platelets. Such a microstructure is in equilibrium with the Si-rich ternary compound $\tau$ as soon as the fcc-Al solid solution attains saturation in $\mathrm{Ti}$ [23]. Therefore, the heat treatment performed on bimetallic samples at $535^{\circ} \mathrm{C}$ is expected to lead to the disappearance of the $\mathrm{Al}_{3} \mathrm{Ti}$ and formation of a Si-rich $\tau$ compound. This is indeed observed after the slow cooling characterizing the overmoulding step (see Fig. 2 and 3).

\subsection{Heat treatment at $535^{\circ} \mathrm{C}$ : short times}

For a short heat treatment at $535^{\circ} \mathrm{C}$, the reaction layer sequence observed between $\mathrm{Ti}$ and the $\mathrm{Al}-\mathrm{Si}$ alloy is $\mathrm{Ti} / \tau$ / fcc-Al+Si (see Fig. 10a). During this initial stage, following conversion of the $\mathrm{Al}_{3} \mathrm{Ti}$ formed during aluminizing at high temperature into the intermetallic compound $\tau$, the twophase region of the Al-7wt.\%Si alloy is in direct contact with the reaction layer on the Ti substrate. In this situation, the thermodynamic activities of $\mathrm{Si}$ and $\mathrm{Al}$ on the interface are both fixed at high values, 1 and 0.987 respectively (according to the thermodynamic modelling of Liu et al. [23] and considering Si diamond and Al-fcc as reference states).

\subsection{Heat treatment at $535^{\circ} \mathrm{C}$ : intermediate times, shorter than $40 \mathrm{~h}$}

Due to the difference in Si content between the Al-7wt.\%Si alloy and the $\tau$ compound (respectively $0.187 \mathrm{~g}$ of Si per $\mathrm{cm}^{-3}$ and $1.844 \mathrm{~g}$ of Si per $\mathrm{cm}^{-3}$ ), the growth of the $\tau$ layer induces a depletion in $\mathrm{Si}$ crystals in the Al-Si alloys, leading to the formation of a one-phase layer of Al solid solution without any Si platelets. This step of the interdiffusion process is therefore characterized by the reaction layer sequence Ti / $\tau$ / fcc-Al / fcc-Al+Si (see Fig. 10b). TEM observations of the interface confirmed the absence of any intermediate phases at the $\mathrm{Ti} / \tau$ interface, revealing that this internal interface of the reaction layer is not in thermodynamic equilibrium. As a consequence, the whole reaction layer sequence cannot be considered as a diffusion path.

\subsection{Heat treatment at $535^{\circ} \mathrm{C}$ : times longer than $40 \mathrm{~h}$}

After 40h of treatment, a dramatic change in the reaction layer sequence is observed with the formation of $\mathrm{Al}_{3} \mathrm{Ti}$ as a thick layer that is embedded in the previously-formed $\tau$ phase. The observed reaction layer sequence is therefore given by $\mathrm{Ti}_{\mathrm{i}} / \mathrm{Al}_{3} \mathrm{Ti}+\tau / \tau / \mathrm{Al}_{3} \mathrm{Ti}+\tau / \mathrm{Al}{ }_{3} \mathrm{Ti} /$ fcc-Al / fcc-Al+Si. It should be noted that even after $200 \mathrm{~h}$ hours of treatment, no other phases are depicted by TEM analysis at the $\mathrm{Ti} / \mathrm{Al}_{3} \mathrm{Ti}$ interface, revealing a non-equilibrium condition. Therefore, even after such a long treatment, an equilibrium reaction layer sequence is yet to be established and the one observed cannot be considered as a true diffusion path. van Loo and Rieck already reported on missing phases in Al-Ti diffusion couples ( $\mathrm{TiAl}_{2}$, $\mathrm{TiAl}$ and $\mathrm{Ti}_{3} \mathrm{Al}$ ) because of their slow growth kinetics compared to the one of $\mathrm{Al}_{3} \mathrm{Ti}$ [28]. In the present case, missing phases at the 
interface between the $\mathrm{Ti}$ sheet and the $\left(\mathrm{Al}_{(1-x)} \mathrm{Si}_{\mathrm{x}}\right)_{3} \mathrm{Ti}$ aluminide could certainly be explained by the same kinetics reasons.

The transition leading to the formation of $\mathrm{Al}_{3} \mathrm{Ti}$ is explained by the continuous increase in fcc-Al layer thickness: in this one-phase layer, the chemical potential of the $\mathrm{Si}$ is not fixed and is expected to decrease along the interface with the Ti substrate and inside the reaction layer as the distance from the Si source increases. When a critical value is reached, the conditions are fulfilled for nucleation and growth of the $\mathrm{Al}_{3} \mathrm{Ti}$ phase, leading to progressive consumption of the $\tau$ compound. However, the Si content of the aluminide, which is about 14at.\% (12wt.\%), remains higher than that of the Al-7wt.\%Si alloy acting as the Si source. As a consequence, the fcc-Al layer thickness continues to increase and the Si chemical potential on the Ti substrate to decrease.

Attempts with heat treatment times longer than $200 \mathrm{~h}$ were not successful for two reasons: firstly, it was difficult to maintain the existence of a semi-infinite diffusion couple due to the consumption of $\mathrm{Si}$, leading to disappearance of the $\mathrm{Si}$ source. Secondly, disruption of the contact at the fcc-Al / $\mathrm{Al}_{3} \mathrm{Ti}$ interface was observed, mainly because of oxygen penetration along microcracks. As a consequence, the final transition in the reaction layer sequence towards its stationary composition could not be observed. However, the expected change is the progressive disappearance of the $\tau$ layer embedded in the $\mathrm{Al}_{3} \mathrm{Ti}$ and the appearance of other titanium aluminides at the $\mathrm{Ti} / \mathrm{Al}_{3} \mathrm{Ti}$ interface, leading possibly to identification of the reaction layer sequence towards an equilibrium diffusion path. Disappearance of the $\tau$ layer will be favoured by the decrease in the Si chemical potential in the $\mathrm{Al}_{3} \mathrm{Ti}$ layer because of the increasing distance from the Si source.

Lastly, reactivity between the biphasic Al-7wt.\%Si alloy and $\mathrm{Ti}$ at $535^{\circ} \mathrm{C}$ is mainly characterized by the duration of the transient stage during which the reaction layer sequence changes continuously before reaching almost stationary conditions. The first phases to form are Si-rich, i.e. silicides, while the phases corresponding to the stationary sequence are aluminides. The time required to reach stationary conditions is estimated to be greater than 200 hours. Such behaviour is explained by the conjunction of two conditions: (i) the biphasic nature of one of the diffusion couple end-members with high activity for both elements, both competing with the third one (Ti) to react and form new compounds, and (ii) the huge difference between the composition of the first phase formed at the initial interface and the composition of the biphasic end-member. For other systems that fulfil these two conditions, the same difficulty in reaching stationary conditions for reaction layer growth is hence likely be observed.

This could be the case in the study by Dickson et al. on solid-state interdiffusion between $\mathrm{Zr}$ and $\mathrm{Al}-\mathrm{Si}$ alloys [11]. Several phases are detected in the interfacial reaction zone after $240 \mathrm{~h}$ of heat treatment at $560^{\circ} \mathrm{C}$ between $\mathrm{Zr}$ and several $\mathrm{Al}-\mathrm{Si}$ alloys containing 2 to $5 \mathrm{wt} . \% \mathrm{Si}$ : $\mathrm{Al} 3 \mathrm{Zr}$ with $\mathrm{Si}$ substitution as well as silicides and some ternary compounds. However, as only one heat treatment time was investigated, it is not possible to conclude as to the nature of the reaction layer sequence that is reported: it may be either a transient one or the true final stationary equilibrium. Depending on the case, the layer thicknesses determined in the study may either have reached relatively stationary values or still be moving towards these values. 

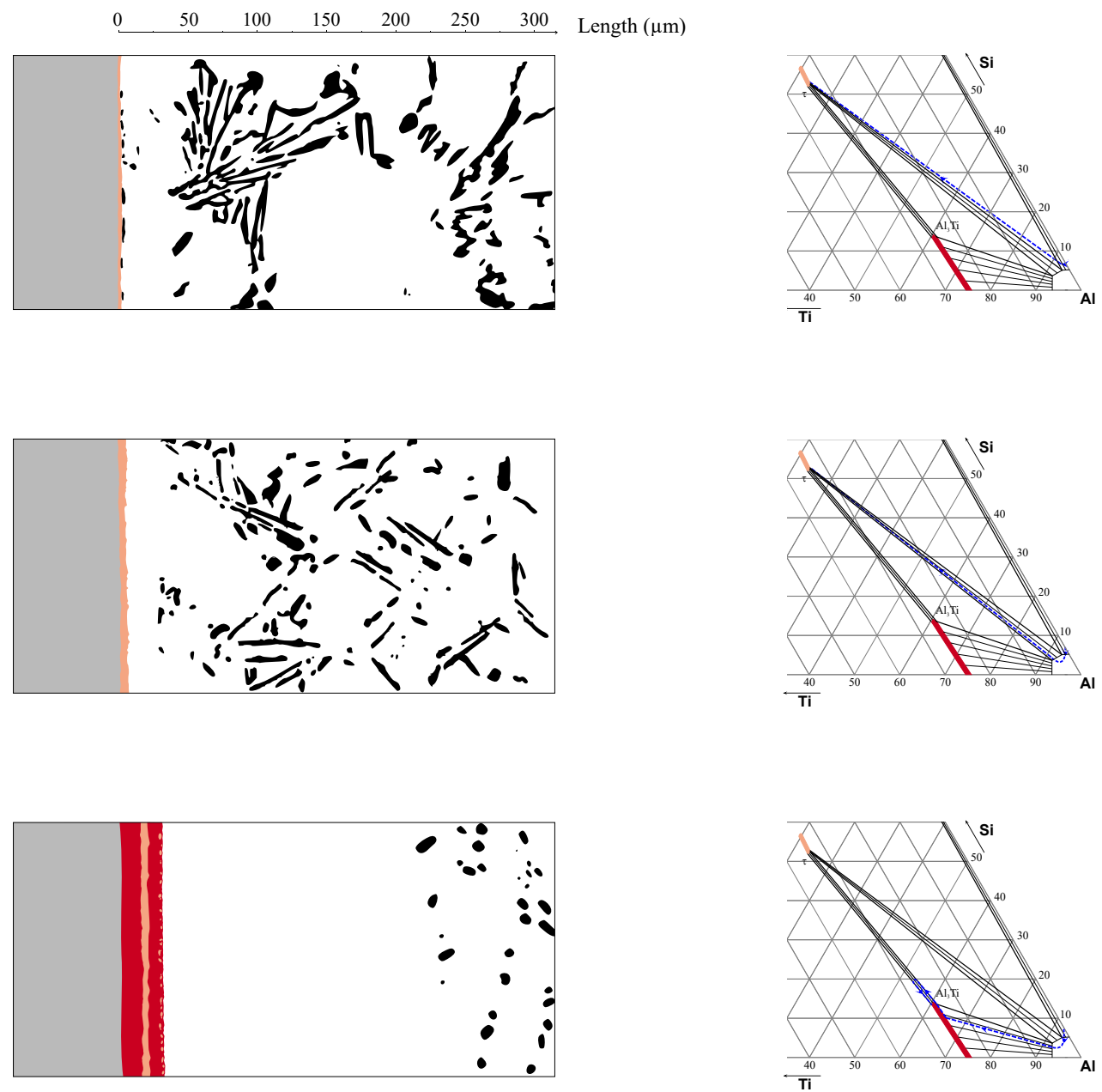

Fig. 10: Left: scale drawings of the changes in the interfacial reaction layer observed experimentally during heat treatment at $535^{\circ} \mathrm{C}$. Right: corresponding reaction layer sequence drawn on the accepted isothermal section of the Al-Si-Ti system at $535^{\circ} \mathrm{C}$. 


\section{Conclusion}

Diffusion couples of Ti and biphasic alloy Al-7wt $\% \mathrm{Si}$ were produced and heat treated at $535^{\circ} \mathrm{C}$ for up to 200 hours. The natures and thicknesses of the phases present in the reaction layer sequence were characterized using conventional techniques such as microprobe analysis, X-ray diffraction and transmission electron microscopy.

The first phase to form at the interface during the solid-state heat treatment is a ternary silicide compound labelled as $\tau$ compound. As the Si content of this compound is about 9 times higher than those of the Al-Si alloys, its growth induces the formation of a pure fcc-Al layer near the interface. After $40 \mathrm{~h}$ of treatment, the thickness of the fcc-Al layer is about $50 \mu \mathrm{m}$ and the decrease in Si chemical potential in the interfacial reaction layer is so large that a dramatic change is observed, leading to the formation of the $\mathrm{Al}_{3} \mathrm{Ti}$ aluminide instead of the Si-rich $\tau$ compound initially formed. After $200 \mathrm{~h}$, the maximum heat treatment time attainable in this study, the reaction layer sequence is not yet stationary and equilibrium is not attained with the residual $\tau$ phase embedded in the $\mathrm{Al}_{3} \mathrm{Ti}$ and the absence of other aluminides at the $\mathrm{Al}_{3} \mathrm{Ti} / \mathrm{Ti}$ interface.

The time required to obtain stationary conditions along the whole diffusion couple is a fundamental characteristic of the $\mathrm{Ti} / \mathrm{Al}-\mathrm{Si}$ system. During the transient regime, the reaction pathway varies within the isothermal section of the phase diagram, firstly shifting towards the silicide phases (nearby the Si corner and the Ti-Si binary) before coming back to the aluminide phases along the $\mathrm{Al}-\mathrm{Ti}$ binary. Even after $200 \mathrm{~h}$ of treatment at $535^{\circ} \mathrm{C}$, the reaction layer sequence is not stationary and could not be considered as an equilibrium diffusion path according to the well-accepted definition [1-3].

\section{Acknowledgements}

SEM and EPMA characterizations were performed at the "Centre Technologique des Microstructures, Université Lyon 1". The authors gratefully acknowledge Bertrand Van de Moortele, who prepared Focused Ion Beam samples at the CLYM technological facility. 


\section{References}

1. A. A. Kodentsov, G. F. Bastin, and F. J. J. van Loo, Journal of Alloys and Compounds 320, 207 (2001).

2. Methods for Phase Diagram Determination, J.-C. Zhao (Elsevier, 2007).

3. J. S. Kirkaldy and L. C. Brown, Canadian Metallurgical Quarterly 2, 89 (1963).

4. J. E. Morral, Metall and Mat Trans A 43, 3462 (2012).

5. W. J. Boettinger, S. R. Coriell, C. E. Campbell, and G. B. McFadden, Acta Materialia 48, 481 (2000).

6. X. Q. Ke, J. E. Morral, and Y. Wang, Acta Materialia 76, 463 (2014).

7. M. Danielewski, A. Gusak, B. Bożek, and M. Zajusz, Acta Materialia 108, 68 (2016).

8. K. Wu, N. Zhou, X. Pan, J. E. Morral, and Y. Wang, Acta Materialia 56, 3854 (2008).

9. J. Priimets and Ü. Ugaste, Defect and Diffusion Forum 312-315, (2011).

10. M. J. H. van Dal, M. C. L. P. Pleumeekers, A. A. Kodentsov, and F. J. J. van Loo, Acta Materialia 48, 385 (2000).

11. J. Dickson, L. Zhou, A. Paz y Puente, M. Fu, D. D. Keiser, and Y. H. Sohn, Intermetallics 49, 154 (2014).

12. V. I. Dybkov, Reaction Diffusion and Solid State Chemical Kinetics, 2 Revised (Trans Tech Pubn, 2010).

13. A. Paul, M. J. H. van Dal, A. A. Kodentsov, and F. J. J. van Loo, Acta Materialia 52, 623 (2004).

14. A. A. Kodentsov, M. J. H. van Dal, C. Cserháti, A. Gusak, and F. J. J. van Loo, Defect and Diffusion Forum 194-199, (2001).

15. A. A. Kodentsov, A. Paul, and F. J. J. van Loo, MEKU 95, 258 (2004).

16. O. Dezellus, M. Zhe, F. Bosselet, D. Rouby, and J. C. Viala, Materials Science \& Engineering, A: Structural Materials: Properties, Microstructure and Processing A528, 2795 (2011).

17. G. Guertler, Aluminium (Isernhagen, Germany) 45, 368 (1969).

18. N. Miyamoto, T. Sato, M. Horigome, G. Saito, T. Mihara, N. Yamashita, K. Shibata, T. Takami, and M. Hirano, WO2007007826 (18 January 2007).

19. N. Eustathopoulos, M. G. Nicholas, and B. Drevet, Wettability at High Temperatures, 2nd ed. (Pergamon, 1999).

20. P. Protsenko, A. Terlain, M. Jeymond, and N. Eustathopoulos, Journal of Nuclear Materials 307-311, 1396 (2002).

21. P. Protsenko, A. Terlain, V. Traskine, and N. Eustathopoulos, Scripta Materialia 45, 1439 (2001).

22. P. Perrot, in Ternary Alloys, edited by G. Petzow and G. Effenberg (VCH, Weinheim FRG, 1988), p. 557.

23. S. Liu, F. Weitzer, J. C. Schuster, N. Krendelsberger, and Y. Du, Int. J. Mat. Res. (Formerly Z. Metallkd.) 99, 705 (2008).

24. C. Brukl, H. Nowotny, O. Schob, and F. Benesovsky, Monatshefte F r Chemie 92, 781 (1961).

25. A. Raman and K. Schubert, Zeitschrift Fur Metallkunde 56, 44 (1965).

26. S. Gupta, Materials Characterization 49, 321 (2002).

27. O. Dezellus, B. Gardiola, J. Andrieux, M. Lomello-Tafin, and J. C. Viala, J. Phase Equilib. Diffus. 35, 137 (2014)

28. F. J. J. van Loo and G. D. Rieck, Acta Metallurgica 21, 61 (1973). 


\section{Figures and tables}

Fig. 1: SEM micrograph of as-cast sample showing the thin $\mathrm{Al}_{3}$ Ti reaction layer

Fig. 2: XRD pattern recorded on the reaction layer formed between Al-7wt.\%Si alloy and Ti sheet after removal of Al-7wt.\%Si aluminizing layer by basic dissolution in $\mathrm{NaOH}$ : (a) after the first aluminizing step followed by water quenching; (b) after aluminizing, overmoulding and cooling in a graphite die at a slow cooling rate

Fig. 3: TEM micrographs of the interfacial region between $\mathrm{Ti}$ and the Al-7wt.\%Si alloy after aluminizing at $730^{\circ} \mathrm{C}$ and overmoulding at $680^{\circ} \mathrm{C}$. EDS analysis and Selected Area Electron Diffraction diagram performed on some grains of Zone 2 confirm the presence of $\tau$ phase.

Fig. 4: Optical micrographs of the Ti/Al-Si7wt.\%Si interface after aluminizing, overmoulding and several heat treatment times at $535^{\circ} \mathrm{C}: 40 \mathrm{~h}, 90 \mathrm{~h}$ and $140 \mathrm{~h}$ (magnification is the same for all micrographs).

Fig. 5: Left hand side: variation in the total thickness of the interfacial reaction layer with up to $200 \mathrm{~h}$ of treatment at $535^{\circ} \mathrm{C}$. Filled circles correspond to a one-phase reaction layer ( $\tau$ phase), while filled triangles correspond to a biphasic reaction layer with the formation of $\left(\mathrm{Al}_{(1-x)} \mathrm{Si}_{\times}\right)_{3} \mathrm{Ti}$.

Right hand side: variation in the thickness of the pure fcc-Al layer that is formed from the Al$7 \mathrm{wt} . \% \mathrm{Si}$ matrix by the total consumption of Si platelets. Once again, filled circles correspond to a one-phase reaction layer, while filled triangles correspond to a biphasic reaction layer.

Fig. 6: comparison of XRD patterns recorded on the interfacial reaction layer after removal of Al$7 \mathrm{wt} . \% \mathrm{Si}$ alloy by basic dissolution in $\mathrm{NaOH}$ between: (a) a sample after $15 \mathrm{~h}$ of isothermal holding at $535^{\circ} \mathrm{C}$, and (b) an as-cast sample after aluminizing and overmoulding.

Fig. 7: composition profiles determined by EPMA analyses across the reaction layers formed between Ti and the Al-7wt.\%Si alloy, (a) for the as-cast sample and after (b) 15h, (c) 90h, (d) 200h of isothermal holding at $535^{\circ} \mathrm{C}$.

Fig. 8: SEM micrograph of interface between Ti and the Al-7wt.\%Si alloy after 200h of heat treatment at $535^{\circ} \mathrm{C}$ showing the development of $\mathrm{Al}_{3} \mathrm{Ti}$ through the whole interdiffusion zone.

Fig. 9: TEM micrograph of the interfacial region between $\mathrm{Ti}$ and the Al-7wt.\%Si alloy after aluminizing at $730^{\circ} \mathrm{C}$, overmoulding at $680^{\circ} \mathrm{C}$ and $160 \mathrm{~h}$ of treatment at $535^{\circ} \mathrm{C}$ : (a) micrograph, (b) characteristic SAD patterns taken from the black grain in 8a, and (c) calculated SAD pattern of $\mathrm{Al}_{3} \mathrm{Ti}$ along the $<-111>$ direction.

Fig. 10: Left: scale drawings of the changes in the interfacial reaction layer observed experimentally during heat treatment at $535^{\circ} \mathrm{C}$. Right: corresponding reaction layer sequence drawn on the accepted isothermal section of the Al-Si-Ti system at $535^{\circ} \mathrm{C}$.

Table 1: The composition (wt.\%) of the A356.2 alloy supplied by ALCAN. 